\title{
Role of health-oriented programs in improving the school's organizational culture
}

Mahnaz Taslimi

* Ph.D. in Educational Management, Islamic Azad University of North Tehran, Tehran. IRAN- Tehran-Iran

\section{Maghsoud Farastkhah}

Ph.D. in planning Higher Education\& Professor in Higher Education of Institute for Research and Planning - Tehran-Iran

Narges Hassanmoradi

Ph.D. in Educational Management\& Associate Professor in Educational Management- North Tehran Islamic Azad - Tehran. - Iran

Received: 07 March 2019

Accepted: 02 October 2019

Doi: $10.29252 /$ ijhehp.8.1.45

\section{ABSTRACT}

Background and Objectives: School organizational culture is one of the most effective assets in promoting school goals and programs and implementing healthoriented programs is one of the important demands of the family along with the education of the students. The purpose of this study was to explain the dimensions of school-based health programs that are instrumental in the development of school organizational culture.

Materials and Methods: In this mix method study, focusing on phenomenological studies was used to gain a deep understanding of the situation under study from the school's ecosystem information. Data were obtained from structured interviews with 30 school principals and staff in the area of health programs and school organizational culture, observations and assessment checklists. Based on the systematic coding method, the main categories were obtained. After obtaining the selected codes, a researcher-made questionnaire was developed. Its validity and reliability were confirmed by test-retest and Its Cronbach ss alpha test was 0.794. Then, a sample of 1329 stakeholders was Surveyed into 5 groups (students, teachers, staff, parents).

Results: The results, while endorsing the categories by the stakeholders, showed that health-based programs are effective in developing school organizational culture through strengthening participatory culture, organizational learning, empowering and strengthening citizenship culture.

Conclusion: The essence of health-oriented programs is a cultural program, both based on knowledge, beliefs, attitudes and behaviors in identifying the future lives of students and the community. These influential programs in the area of school organizational culture that need for health of their audiences, as an effective tool for school success, should be the focus by educational planners and leadership. Keywords: School organizational culture, school culture, health management, health-oriented programs, health promotion.

Paper Type: Research Article.

Citation (Vancouver): Taslimi M, Farastkhah M, Hassanmoradi N. Role of healthoriented programs in improving the school's organizational culture. Iran J Health Educ Health Promot. Spring 2020;8(1): 45-56. [Persian]

> Citation (APA): Taslimi M., Farastkhah M., Hassanmoradi N. (Spring 2020). Role of health-oriented programs in improving the school's organizational culture. Iranian Journal of Health Education \& Health Promotion., 8(1), 45-56 . [Persian] 


\section{نقش برنامههاى سلامت محور در توسعه فرهنكَ سازمانى مدارس}

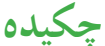

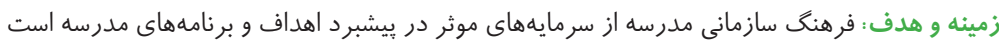

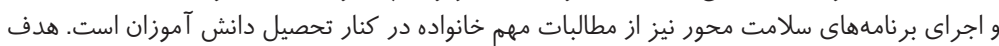

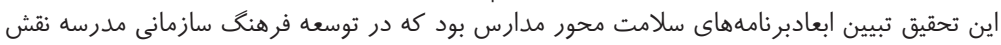
آفرين هستند.

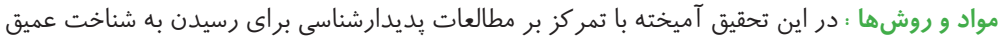

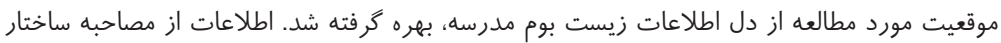

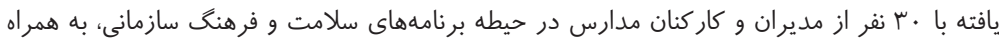

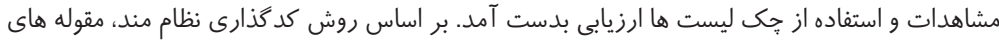

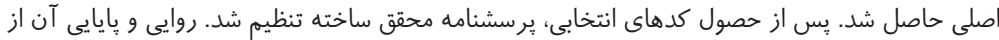

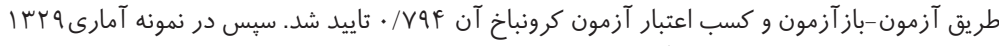

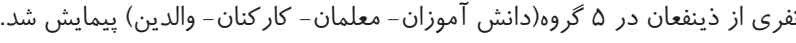

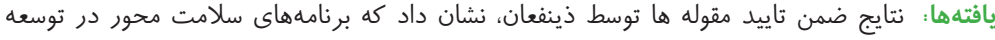

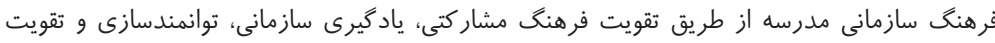

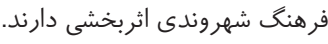

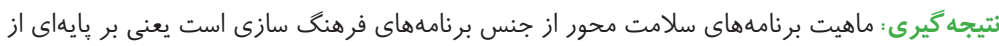

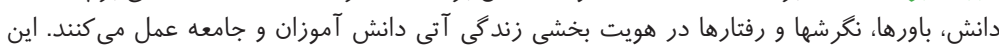

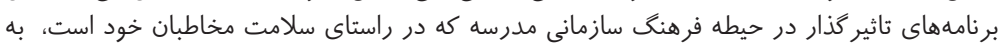

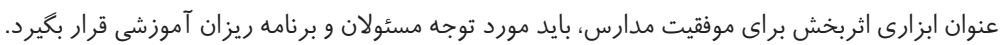

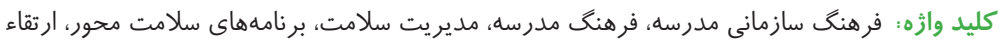

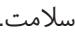

نوع مقاله : مطالعه يزوهشى.

\استناد (ونكوور): تسليمى م، فراستخواه م، حسن مر ادى ن. نقش برنامههاى سلامت محور در توسعه

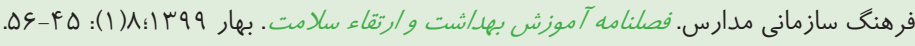

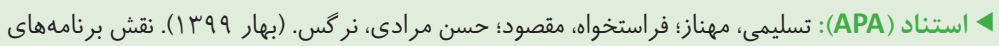

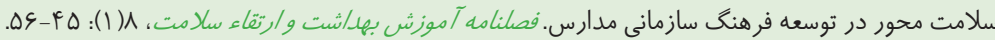

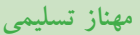
دانش آموخته دكتراى مديريت آموزشى، دانشكده مدير يت،دانشكاه آزاد تهران شمال. تهران، ايران دئ دان مقصود فر استخو اه

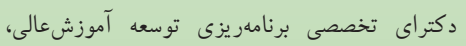

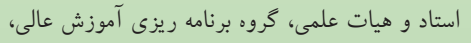

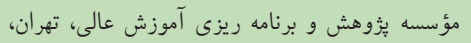

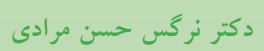
دكتراى تخصصى مديريت آموزشى، دانشيار و هيات

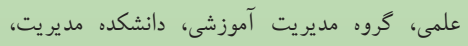
دانشعاء آزاد تهران شمال، تهران، ايران

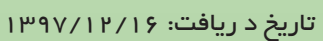
تاريخ يذيرش: 
ايده آل را براى اعضاى مدرسه مفهوم سازى نمايد. مدرسهاى با

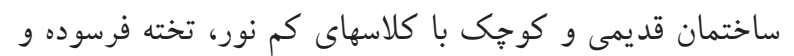
صندليهاى شكسته رغبت به درس و بحث و اثر كذارى ياددهى -

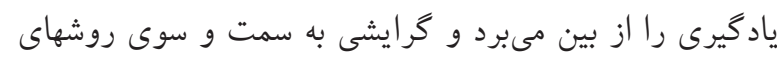
تدريس غير فعال و سخنرانى در معلمان ايجاد مى كند كه انفعال

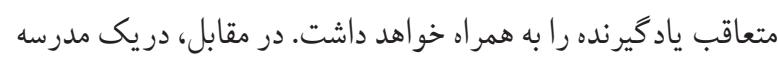

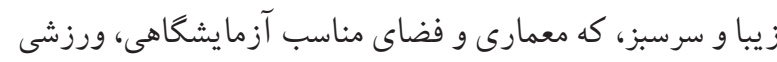

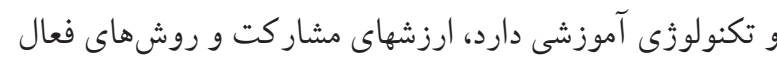

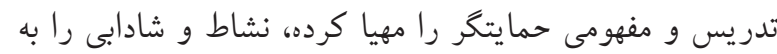

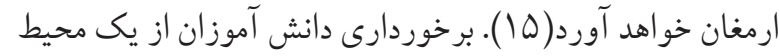

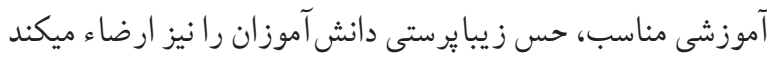

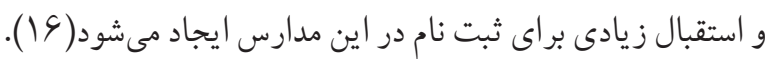
متاسفانه اغلب مدارس كشور در زمينه فضاى آموزشى، استانداردها

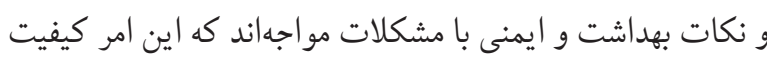

ياد كيرى دانش آموزان را كاهش مى دهد (IV، IN).

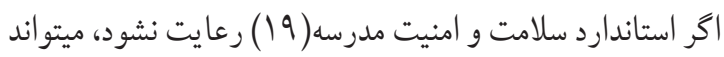

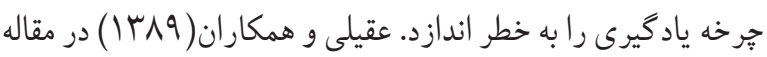
خود در زمينه سيستم مديريت سلامت در مدارس كشور، نتيجه كرفتند

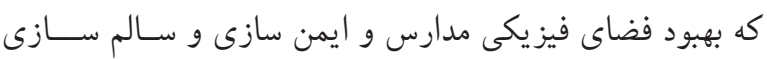

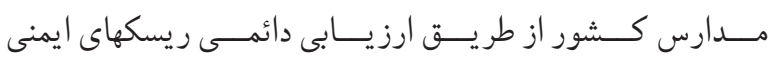
و بهداشت باعث نهادينه شدن آموزش فرهنگ سلامت در ميان

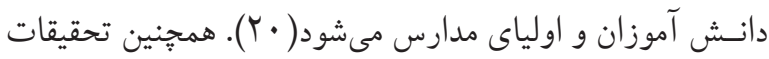

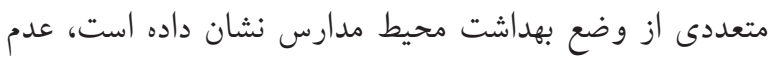

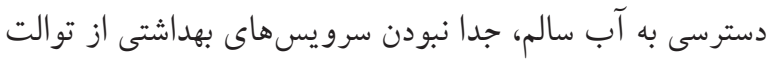

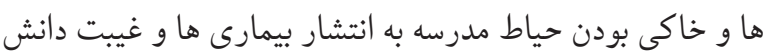
آموزان منجر شده است. عدم رعايت شاخص هاى بهداشت محيط

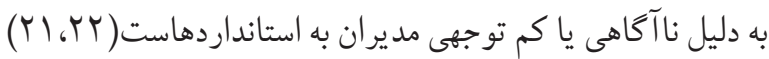

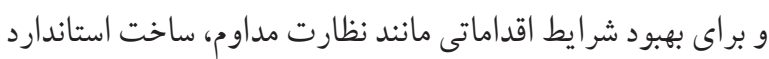

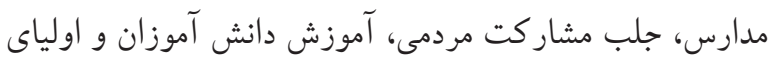

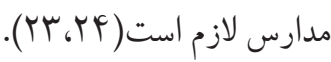

فرهنگ مدرسه و نقش آن در مدرسه ها از موضوعات در حال رشد

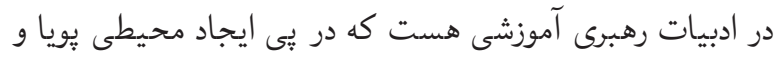
با نشاط با هدف زمينه سازى براى تربيت انسانهايى است كه با دهبي

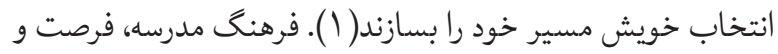

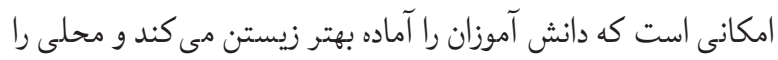
فراهم مى كند كه در آن نمى توان بين زيستن و آموختن تمايزى قائل

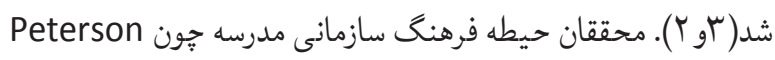
،(V)Firestone,W.A (צ) Steve Gruenert ، ( $)$ ( $(\mathcal{Y})$ \&Deal Fullan ،( $(\cdot)$ Wagner (9)Higgins ،( $)$ Hargreaves

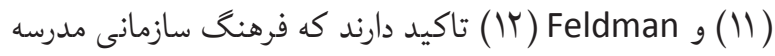
مجموعهاى از هنجارها، ارزش ها و اعتقادات، آداب و رسوم و مراسم،

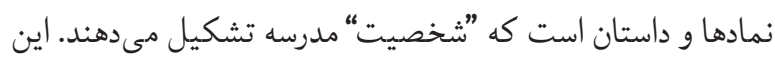
انتظارات نانوشته و نامحسوس سبب مىشود كه در طول زمانها

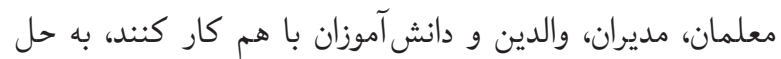

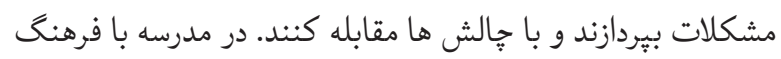
مثبت، يادگيرى كاركنان و دانش آموزان بيشرفت صحيح دارد. در

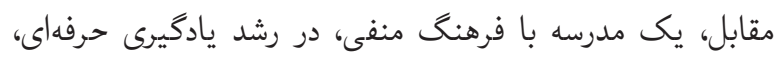
ارزشى ندارد و به علت مقاومت در برابر تغيير، مانع موفقيت است.

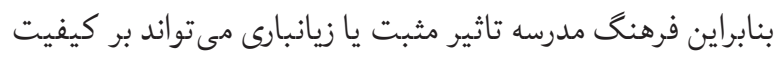

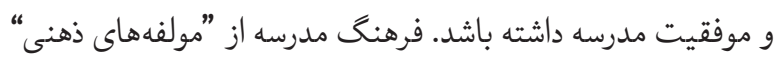

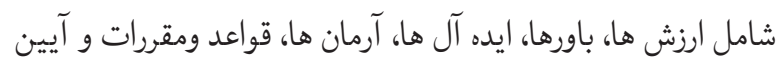
نامهاى رسمى ادارى و "مولفههاى عينى" يعنى مجموعه نشانه هاو نمادهاى مادى و معنوى تشكيل دهندهى فضاى نمادين شكل گرفته

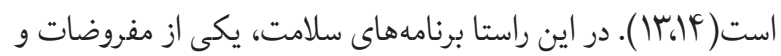

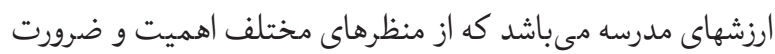
آن در تعالى فرهنگ سازمانى مدرسه قابل تامل است. از منظر ساختار فيزيكى مدرسه و عناصر تشكيل دهنده آن مدرسي

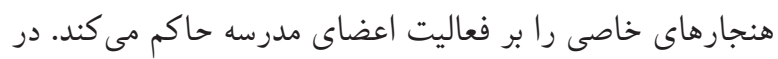
حقيقت مولفه مكان و محيط فيزيكى مدرسه و كلاس درس مى تواند نقش آفر ينى معلمان را جهت بخشد و تصوير متفاوتى از ياد خيرنده 


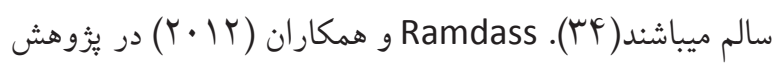
خود در مورد عوامل سلامت سازمانى مدارس، به اهميت محيط

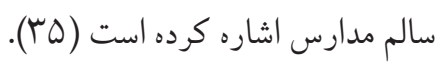

از منظر كذر اجتماعى در كشورهاى در حال يّيشرفت، به علت

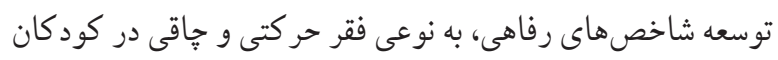

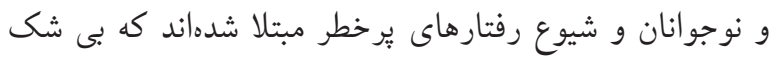

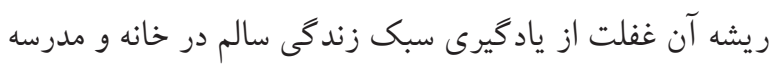

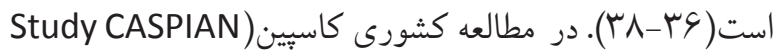
) كه به صورت مقطعى تحت عنوان (اطرح ملى نظام مراقبت و

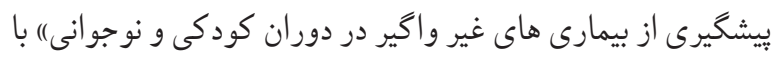

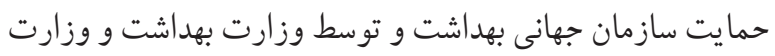

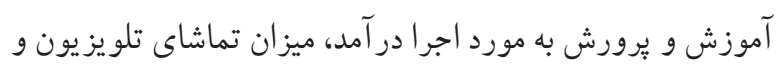

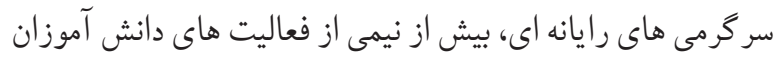

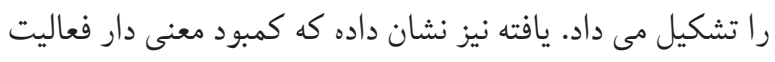

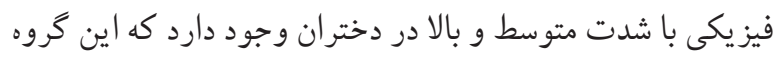

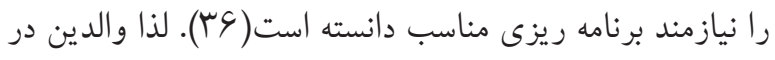

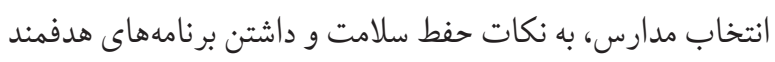
در حيطه سلامت در مدرسه تاكيد زيادى دارند( (؟). سلامت كاركنان مدارس، نيز در فرهنگ مدرسه سالم مورد

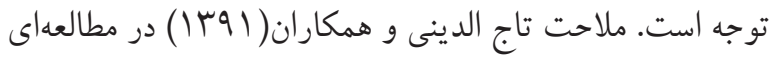
با عنوان رابطه فرهنگ سازمانى با عملكرد ايمنى، بهداشت و محيط

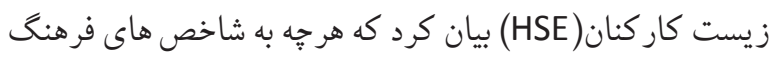

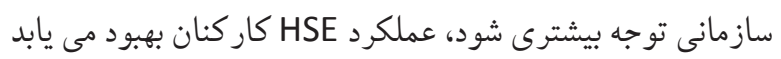

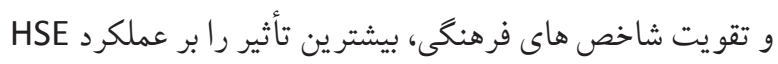

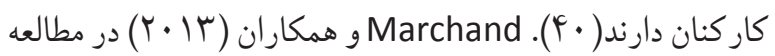

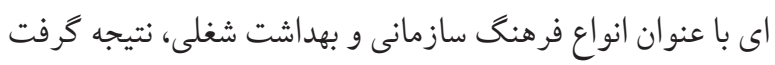

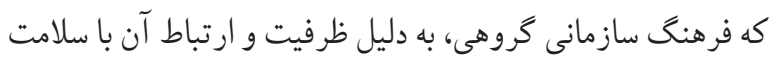

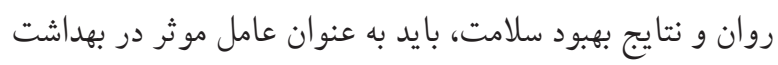

حرفهاى در نظر كرفته شود ( (1).

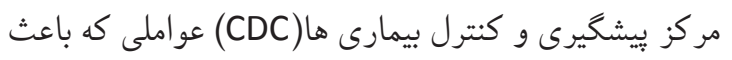

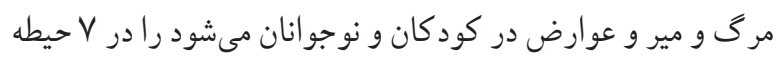

يافتهاى تحقيقات J Coe D Pivarnik و همكاران( ؟ . † ) بر همبستكى نتايج آكادميك دانش آموزان با فعاليت هاى تربيت

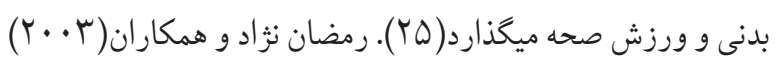

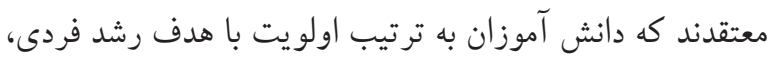
هدف تعامل اجتماعى و هدف ساز كارى محيطى در كلاسهاى تربيت

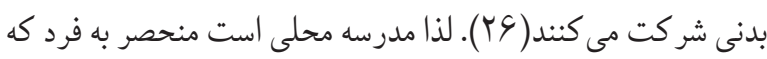

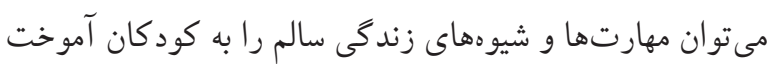

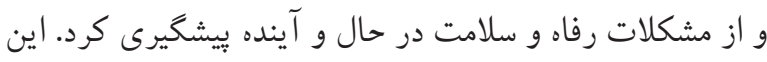

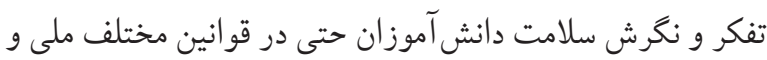

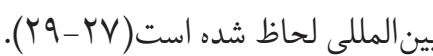
شبكه ارتقاء بهداشت مدارس ارو ڤا (The European Network of Health Promoting Schools-ENHPS

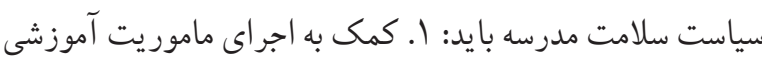

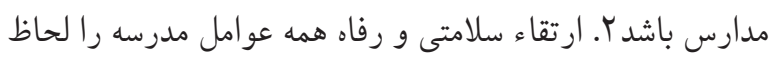

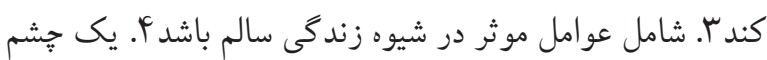

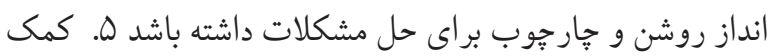

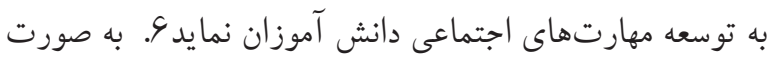
منظم برنامه ارزيابى داشته باشد( • (ץ).

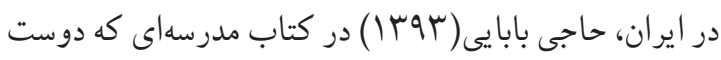
دارم، به خصوصيات مدرسه مطلوب، اشاره كرده است كه ال إمورد

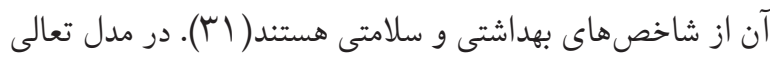

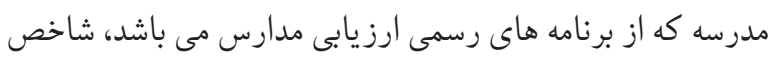

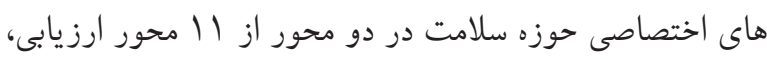

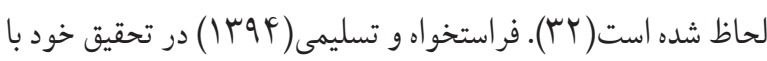
عنوان فرهنگ سازمانى مدارس غير انتفاعى گو يههاى حيطه سلامت

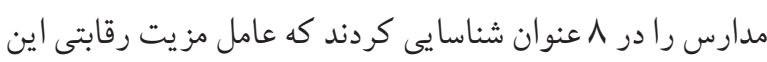
مدارس محسوب مىشود(س مبر).

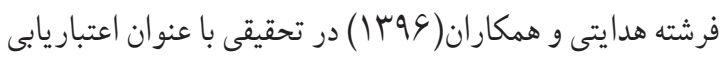
مدل مفهومى مدرسه سالم با تاكيد بر سلامت سازمانى مدرسه، نتيجه گرفت كه مضامينى جون ويز گیىهاى دموكر افيك مدرسه و سلامت دانش آموزان از مهمتر ين عوامل تشكيل دهنده مدرسه 
مدرك كارشناسى و سابقه بالاى ه سال مديريت در مدارس معرفى

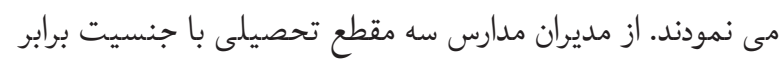

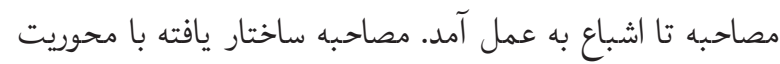

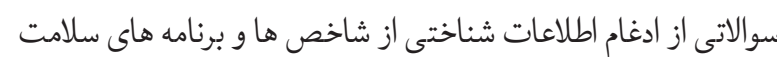

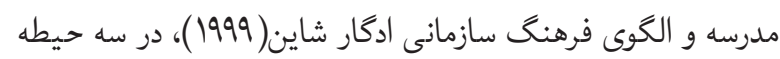
I. زندكى سازمان r. شبكه انسانى سازمان سا. باورهاى نهفته سازمان

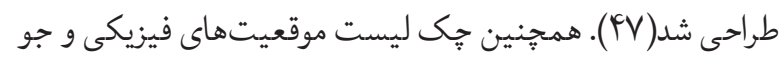

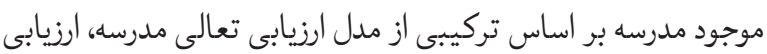

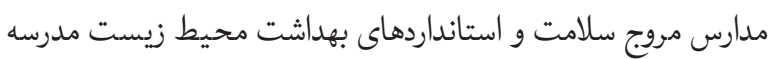
(T. ) (HSE) طبق مشاهده و نظرسنجى تكميل شد. كليه اطلاعات و گزارههاى دريافتى مصاحبه ها كه ثبت و نكارش شده بود، با كدگذارى جند مرحلهاى(روش كدگذارى نظام مند اشتراوس و كوربين- •199) به سمت

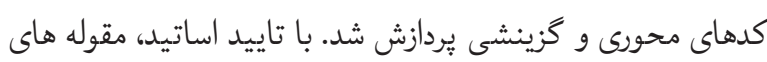

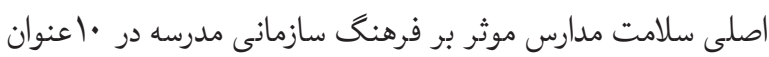

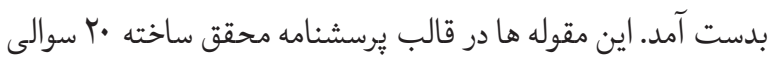

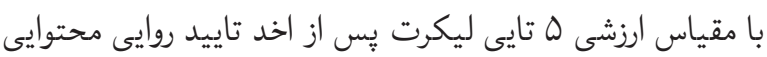

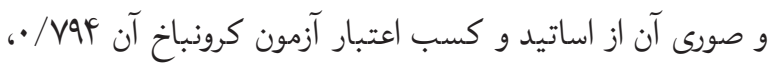

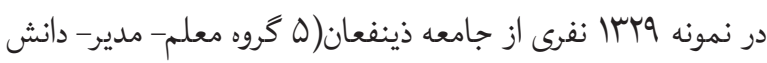

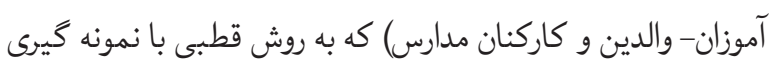
تصادفى منظم بدست آمد، بيمايش شد و عملا اين تحقيق كيفى مدانى

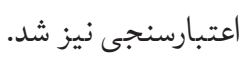

يافتهاه ها

خلاصه مشخصات دموگرافيك مصاحبه شونده ها طبق جدول( ) مىباشد. از داده هاى كيفى تحقيق، أ-مولفه هاى عينى و نمادهاى فرهنگ

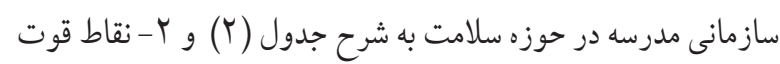
و ضعف شاخص هاى سلامت در فرهنگ مدرسه به شرح جدول(ب)

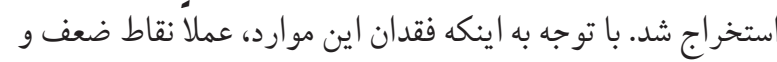
تهديد مدرسه محسوب مىشود، از ذكر مجدد خوددارى شد.
رفتار پرخطر دسته بندى كرده است كه سرمايه كذارى بر روى

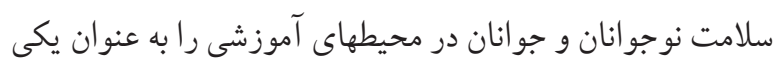

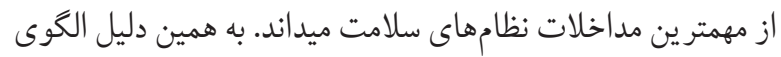
مدارس مروج سلامت(Health Promotion School- HPS) را

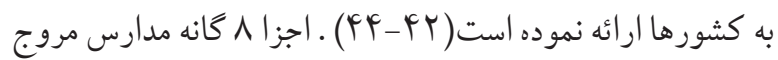

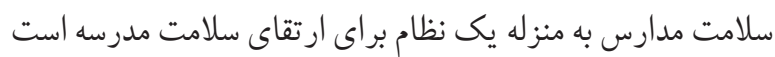

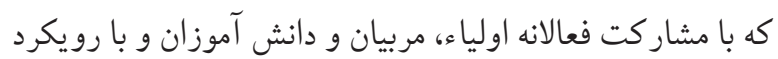

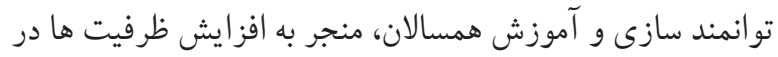

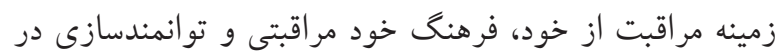

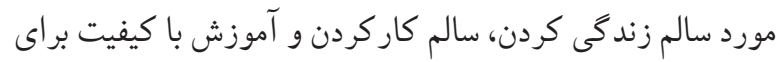

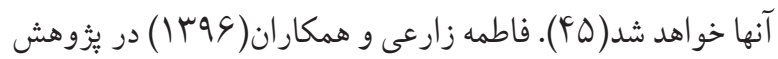
خود با عنوان نقاط قوت و جالشهاى مدارس مروج سلامت، نتيجه كرفتند كه يكى از فاكتورهايى كه بر روى يذيرش اين برنامه اثر

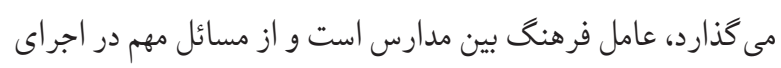

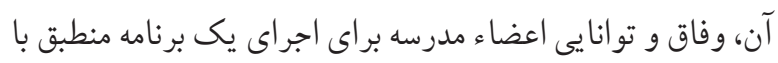

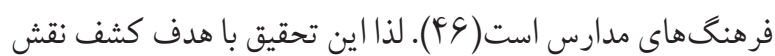

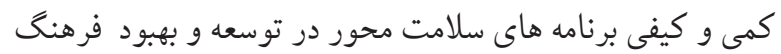
سازمانى مدرسه انجام گرديد.

$$
\text { مو اد و روش ها }
$$

طرح يُوهشى اين تحقيق آميخته بود كه از مطالعات كيفى يديدارشناسى' روسى بهره كرفته شد. اين روش مبتنى بر يك روش استقرايى و با ديدكاه

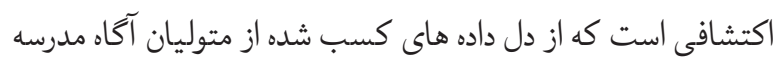

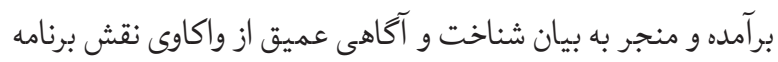
هاى سلامت در فرهنگ سازمان مدرسه مى گردد. از روشهاى مصاحبه ساختار يافته به همراه مشاهده و קك ليست هاى نظرسنجى استفاده

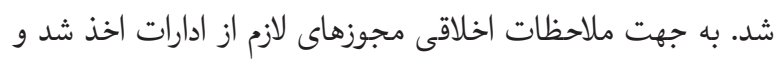

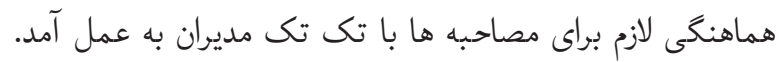

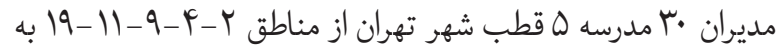

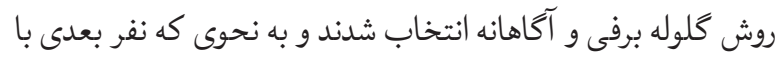


جدول ا. خلاصه دموگرافيك از مصاحبه شوندگًان در مرحله كيفى تحقيق

\begin{tabular}{|c|c|c|c|c|c|c|c|c|c|}
\hline \multicolumn{2}{|c|}{ تحصيلات } & \multicolumn{3}{|c|}{ سنوات مديريت } & \multicolumn{3}{|c|}{ سنوات خدمت } & \multicolumn{2}{|c|}{ جنسيت } \\
\hline كارشناسى & كارشناسى & $r \cdot r l$ & $r \cdot 11$ & زير ·1 & r. & ا r r & زير · r & 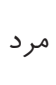 & 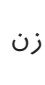 \\
\hline \multirow[t]{2}{*}{$1 \pi$} & $\checkmark$ & $\cdot$ & ro & $\Delta$ & $\wedge$ & $1 \cdot$ & ir & 10 & 10 \\
\hline & & \multicolumn{3}{|c|}{ ميانگين سنوات مديريت: 9,4 } & \multicolumn{3}{|c|}{ ميانگين سنوات خدمت: †, آ } & & \\
\hline
\end{tabular}

جدول r. مولفهاى عينى و نمادهاى مربوط به فرهنى سلامت مدرسه

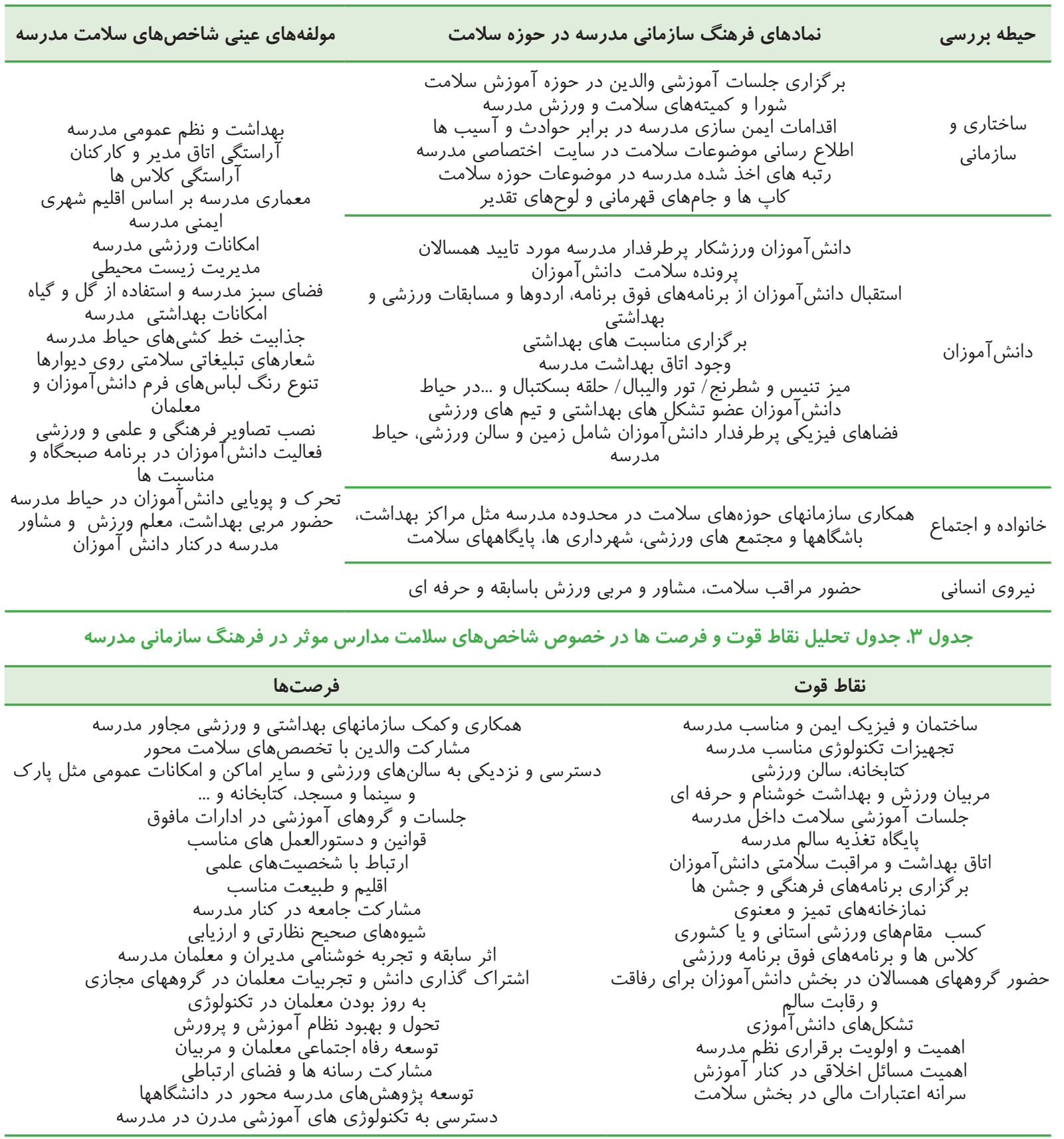


از كد گذارى مفهومى سوالات مصاحبه ها به همراه مسير تقليل در جدول أنهايى شد.

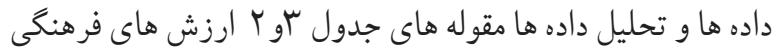

جدول عا. كدهاى انتخابى از مفهومهاى فرهنگى برنامه هاى سلامت محور

\begin{tabular}{|c|c|}
\hline مفهوم هاى فرهنكى استخراجى & حيطه هاى سلامت مدرسه \\
\hline توسعه فرهنگ نشاط اجتماعى & 1. محيط فيزيكى با نشاط و ايمن مدرسه \\
\hline توسعه توانمندسازى فرهـ زيستى & ז.امكانات پشتيبانى و زيرساخت هاى ورزشى و بهداشتى \\
\hline توسعه فرهنگ مشترى مدارى & r. تجهيزات ورزشى، كتابخانه، ملزومات بهداشتى مدرسه \\
\hline توسعه فرهنگ ياد كيرى سازمانى & ז- حضور كار كنان متخصص در مدرسه \\
\hline 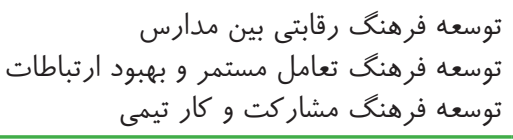 & ه-طرح و برنامههاى سلامت محور \\
\hline توسعه فرهنگ فرهنگ اعتماد متقابل بخشى & 9- قوانين حمايتى موثر و قانونى سلامت محور \\
\hline
\end{tabular}

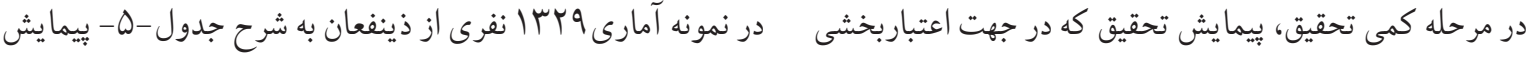

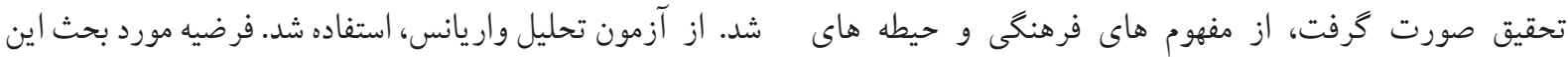

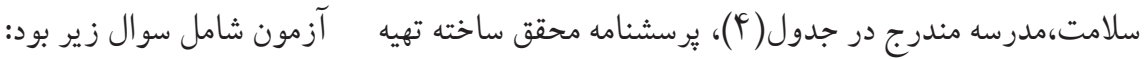

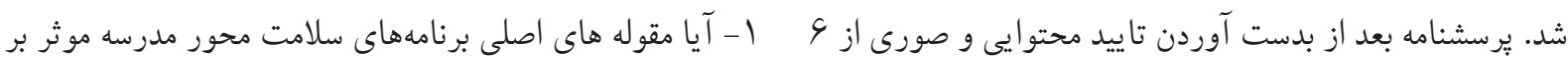

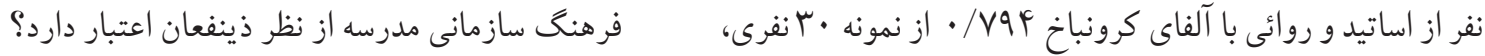

جدول ه. امتيازاهميت شاخص هاى سلامت از ديدكًاه ذينفعان

\begin{tabular}{|c|c|c|c|c|c|}
\hline انحراف معيار & 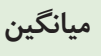 & درصد اهميت مجموع شاخصها & تعداد & كروه آمارى & 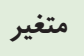 \\
\hline$\cdot / 1 \mathrm{~V}$ & $4 / 19$ & $9 \vee / \wedge$. & r. & 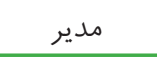 & \multirow{6}{*}{$\begin{array}{c}3 \\
-13 \\
3 \\
3 \\
y \\
2 \\
2 \\
3 \\
13 \\
3 \\
3 \\
3 \\
3 \\
3\end{array}$} \\
\hline.$/ 1 F$ & $r / 9 r$ & $q \wedge / F \vee$ & rvo & معلمان & \\
\hline$\cdot / \mu V$ & $r / \Delta V$ & 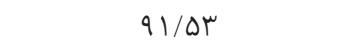 & IVo & كار كنان & \\
\hline$\cdot / r \Lambda$ & $r / s r$ & 94 & $\Delta \cdot \Delta$ & دانش آموزان & \\
\hline$\cdot / r F$ & $r / \Lambda \mu$ & $9 \Delta / \wedge$. & TFF & والدين & \\
\hline$\cdot / \mu$. & c/VD & $90 / 1 \pi$ & qru & مجموع & \\
\hline
\end{tabular}

سطح معنادارى آزمون توكى در رابطه با شاخصهاى سلامت مدرسه در

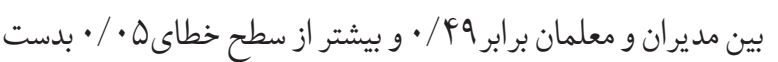
جدول 9 نتايج آزمون آناليز واريانس يكطرفه را نشان مىدهد كه

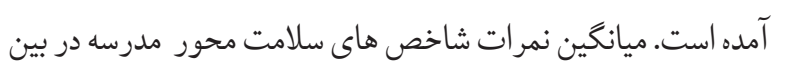

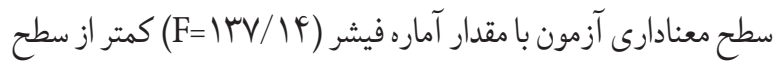

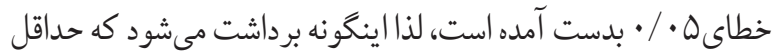
دو گروه آمارى وجود دارند كه ميانكين نمر ات شاخص هاى سلامت مديران و معلمان يكسان بوده و تفاوت معنادارى نداشت. بيشترين ميانكين

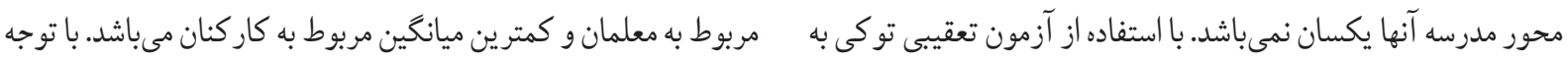

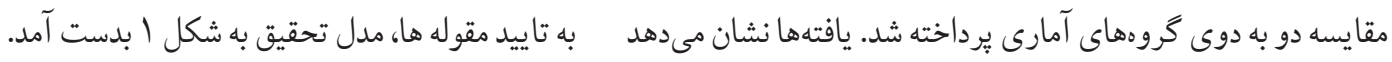


جدول צ. نتايج آزمون آناليز واريانس يكطرفه و آزمون تعقيبى توكى در خصوص مقايسه دو به دويى ذينفعان

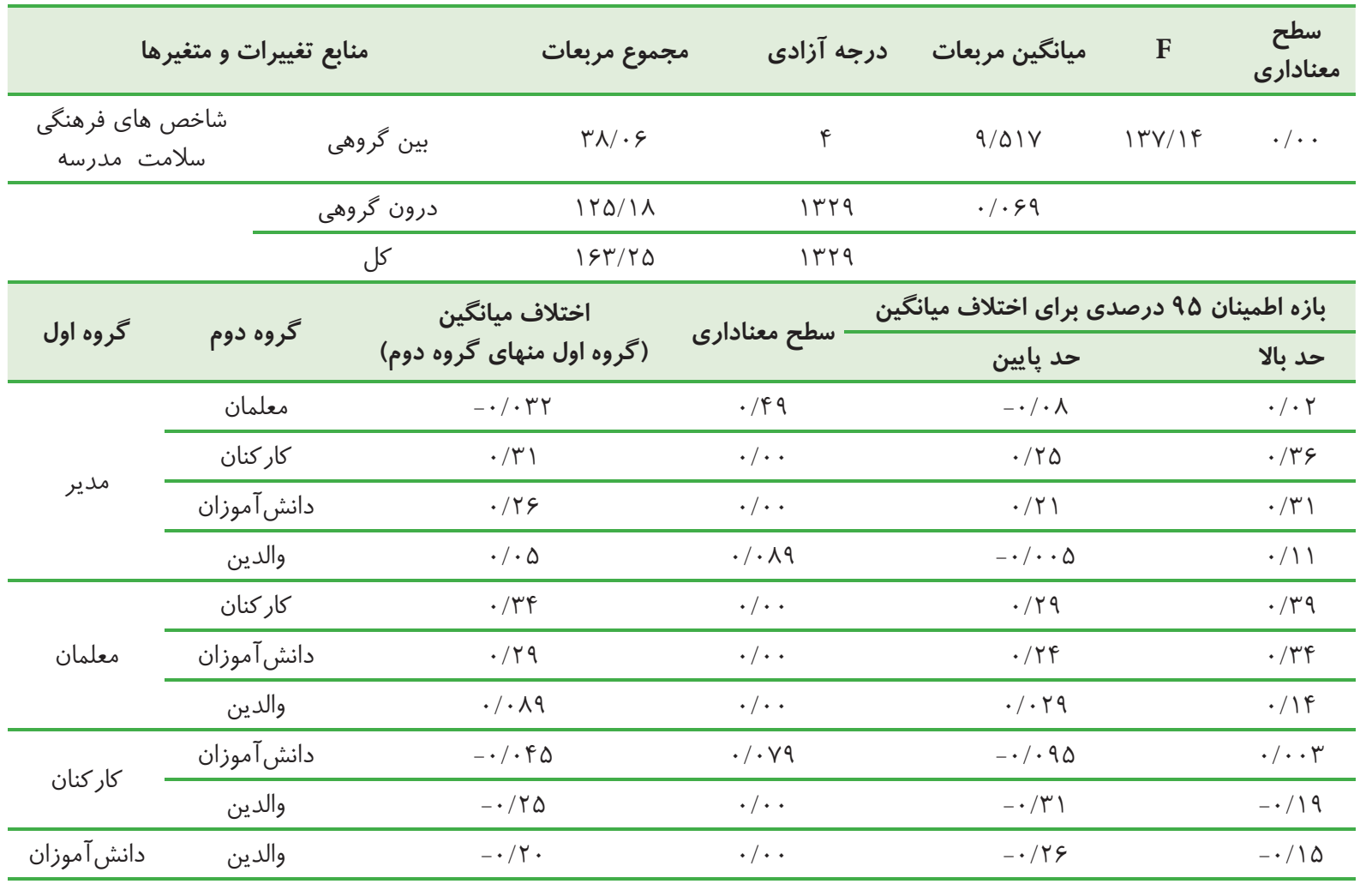

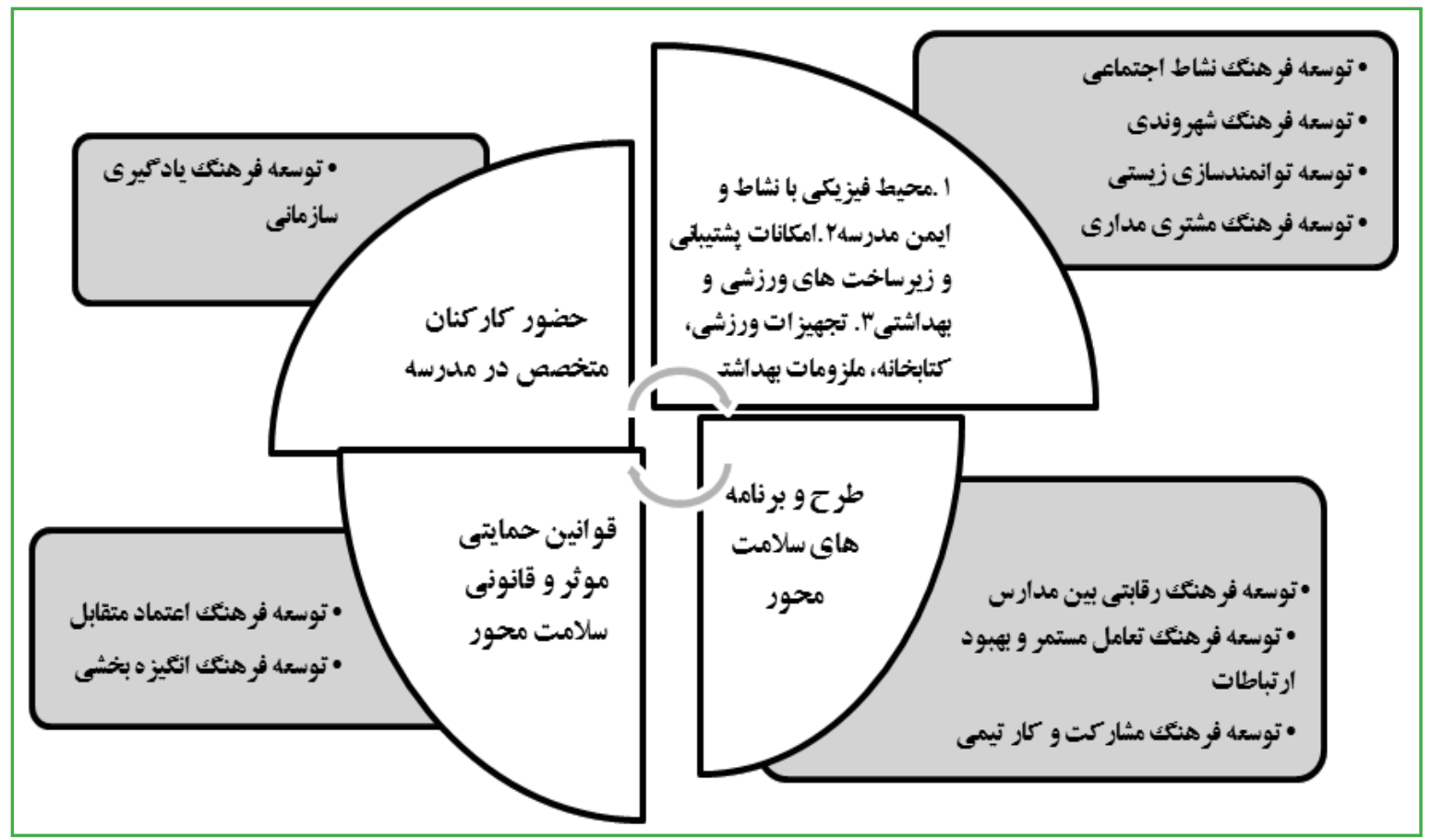

شكل ا. مدل تعاملى شاخص هاى سلامت و فرهنَ سازمانى مدرسه 
كسب هنجارهاى سالم فرهنگ مدرسه است كه از ديدكاه مخاطبان

در عملكرد مدرسه و ييامدهاى آن ملموس مى باشد.

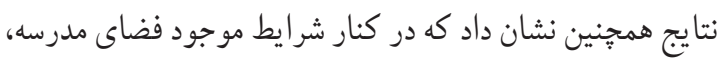

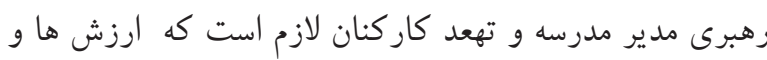

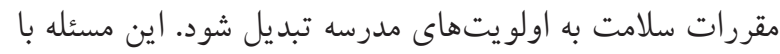

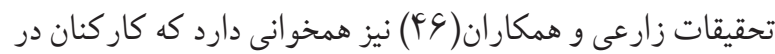

برابر مسئوليتهاى اضافى و غير تخصصى، امكان مقاومت دارندوودر

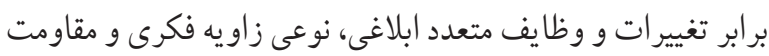

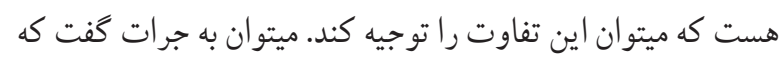

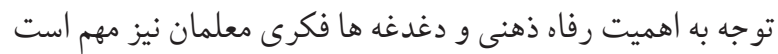

و برنامه هاى سلامت مدرسه نيز بايد ظرفيت كافى و مناسبى براى

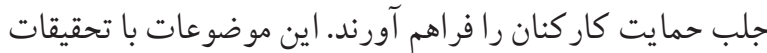

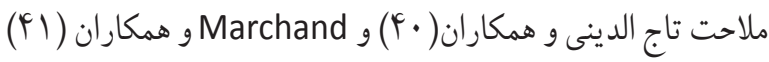
در حمايت فرهنگ سازمانى به سلامت جسمى و روانى كاركنان و اهميت كار گروهى و مشار كتى همخوانى و همر استايى داشت.

$$
\text { نتيجه كيرى }
$$

كودكان و نوجوانان سالم، فرهنگ سالم زيستن را از مدرسه مى آموزند. برنامههاى سلامت مدرسه، ابعاد وسيعى مانند سلامت جسم و روان، هويت فرهنكى و توسعه روانى و اجتماعى را در بر مى گيرد لذا اين يادكيرى فعال، تاثير ماندكارى بر دانش، باورها، نكرش ها

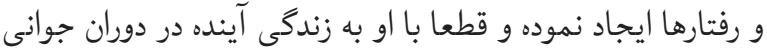

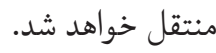

تحقيقات اين ييشنهاد را تقويت ميكندكه مدارس با فرهنگ سازمانى سلامت گرا و به نوعى مدارس مروج سلامت توجه و تاكيد و تمركز فراوانى بر اهداف ارتقاءسلامت مخاطبان خود را مارعا مران

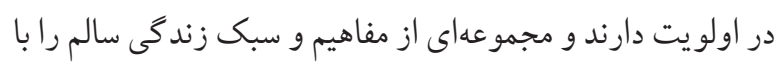
استفاده از مشاركتهاى ذينفعان در جامعه مدرسه ترويج مى كنند. اين مدارس به غير از آموزش برنامههاى درسى مدرسه، سياستها ونكرشها و فعاليتهاى محلى،خدمات ومنابع محلى را در حيطه ارتقاء سلامت دانش آموزان مورد توجه قرار ميدهند تا با همكارى ميان

نتايج تحقيق در بحث شناسايى شاخصهاى سلامت محور مدرسه با نتايج دسته بندى شاخص هاى موثر سلامت از نظر تحقيقات شبكه

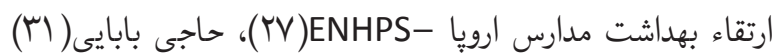

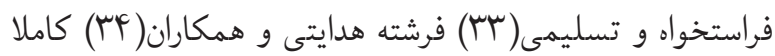

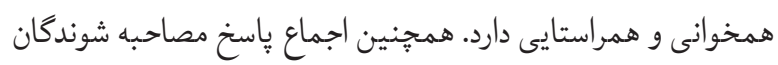

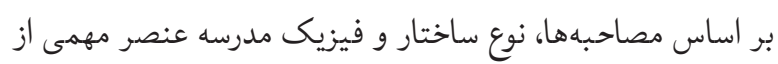

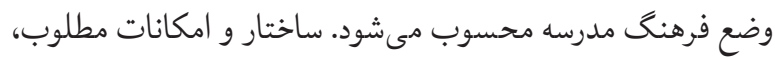

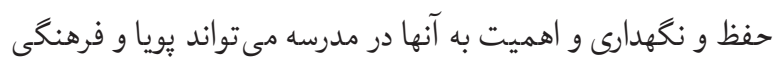

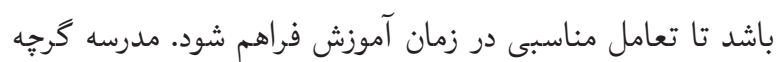

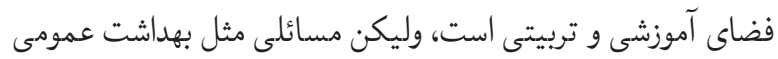
مدرسه، تغذيه مدارس، امكانات سالنهاى ورزشى، طرح هاى بهداشتى و ورزشى و .... فقط بر عهده مدرسه تنها نيست. در اين زمينه، رويكرد مشاركتى منطقهاى و اجتماعى ميتواند موثر و تقويت كننده باشد به نحوى كه رفع دغدغههاى مدرسه باعث ارتقاء كاركردهاى تعليم و تربيت و باتبع توسعه فرهنگ جامعه شود. فراوانى نكات قوت و فرصت شاخص هاى سلامت و نوع تعاملات عملاً نوعى توسعه يافتخى براى مدرسه است و بينش و درو نى عميق

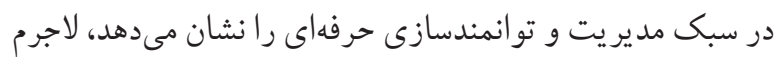

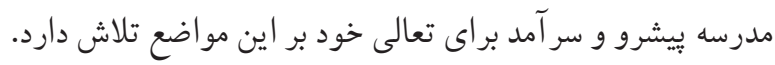

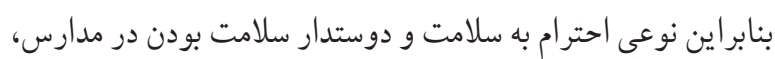

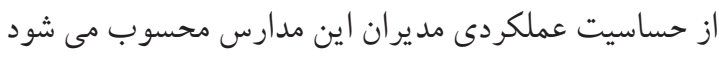

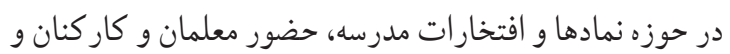
برخى دانش آموزان كه درجات نخبكى و علمى خاصى دارند، ميتو انند

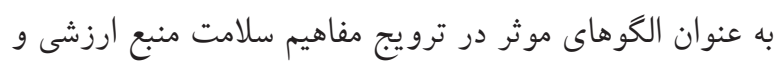
سرمايه اي مدرسه محسوب شوند. ارتباط خانو اده با مدرسه و تعداد جلسات و كميته ها كه براى ارتباط مدرسه با خانو اده ها و كار كنان

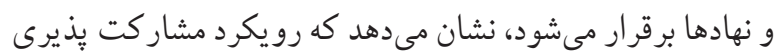

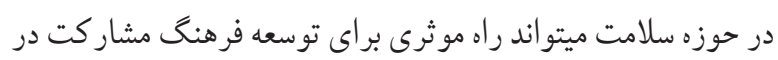

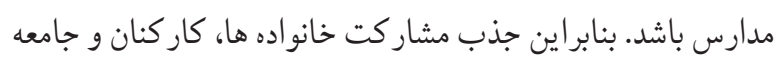

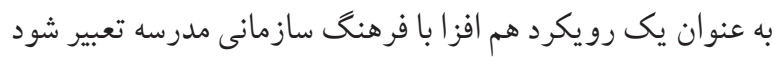


F

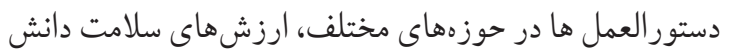
آموزان در جنبههاى مختلف را لحاظ نمايند. حمايت از محققين و حضور متخصصين حوزه سلامت در مدارس باعث تقويت

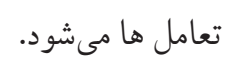
هـ- مديران مدارس: مديران و سريرستان آموزشى مى تو انند در

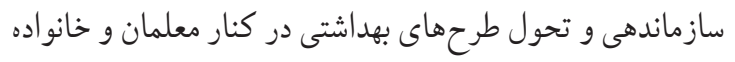
ها و جلب حمايتهاى مالى، در قالب كميتههاى مشورتى، قهرمان برنامههاى بهداشت مدرسه باشند. 9- فرهنگ مدرسه حمايتى و مشار كتى: شيوههاى بهداشتى موفق و

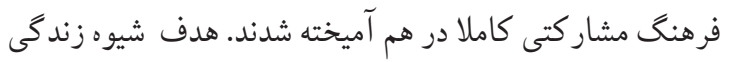
سالم و توسعه مدارس با اهداف فرهنگ سازمانى همراستا و

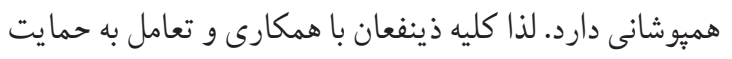
از طرحهاى بهداشت مدرسه بيردازند.

همجنين از آنجا كه اين تحقيق كيفى در مناطق كلان شهر تهران بردان

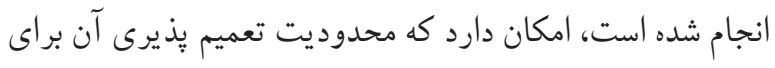
مناطق حاشيهاى و روستايى وجود داشته باشد لذا ييشنهاد ميشود

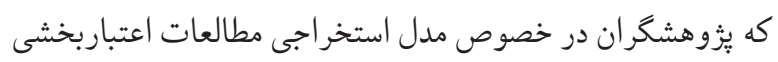
را در شهرهاى ديكر نيز انجام دهند.

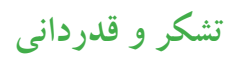
در يايان از زحمات كليه فرهنگيان محترم در مدارس منتخب كه صميمانه همكارى داشتند و استاد فرزانه جناب آقاى دكتر مقصود فراستخواه كه در اين يزوهش يارى داشتند، كمال تشكر دارم.

$$
\text { تقارض در منافع }
$$

بين نويسندگان هيجگُونه تعارض در منافع گزارش نشده است.

\section{References}

1. Goodarzi, Akram et al. Pathology of school culture based on the framework of competitive values. Management styles on organization training. 1394;1: 9 - 41.

2. Zarei F, Ghahremani L, Khazaee-Pool M, Keshavarz Mohammadi N. Exploring The Strengths, Challenges and Improvement Strategy For Health-Promoting Schools From School Health Experts. Iranian Journal of Health
مدرسه، خانه و جامعه كه ركنهاى تفكيك نايذيرى هستند، يك زبان

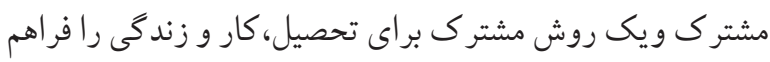
كنند. آنها يقين دارند كه محيط مدرسه براى تعيين سلامت روت آينده

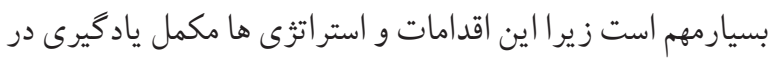
مدرسهاند نه برنامههاي وقت كير . اين تحقيق ضمن تاييد تحقيقات

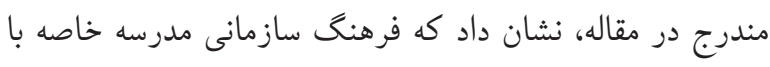

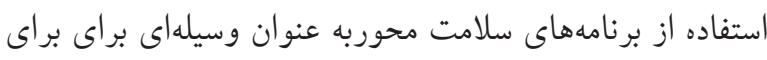

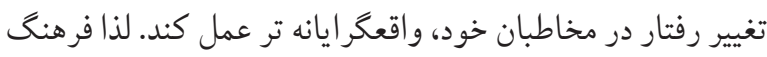
سازمانى مدرسه كه مطالبه جامعه هست بايد از ديد كاههاى ارتقاء

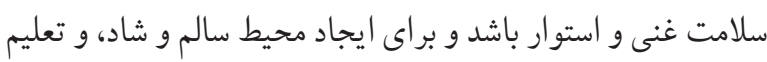

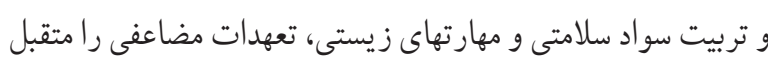

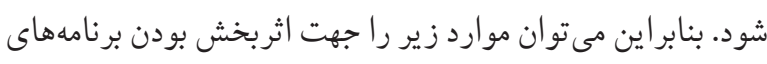
سلامت محور مدرسه در بهبود فرهنگ سازمانى مدارس يشنهاد داد: 1 - افزايش تقاضاى برنامهاى سلامت از سيستم آموزش و يرورش:

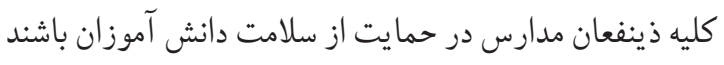
نه احساس شود كه اولويت فقط بايد در تحصيل و درس خواندن،

$$
\text { انتظار از مدرسه است. }
$$

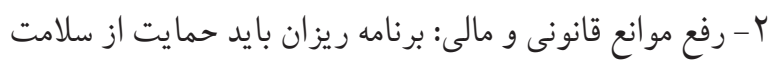

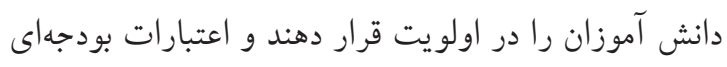

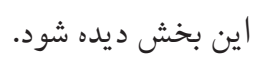

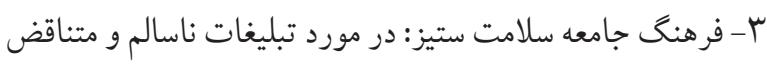

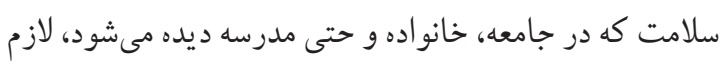

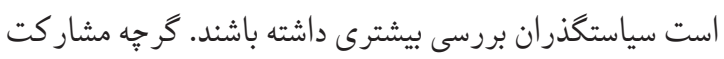

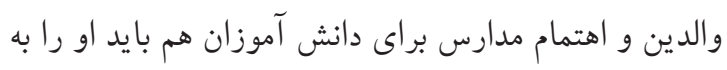
انتخابهاى صحيح تشويق نمايد.

Education and Health Promotion. 2017;5(3):240-50. [DOI:10.30699/acadpub.ijhehp.5.3.240]

3. Rahimi B, Tavassoli E. Measuring Health Literacy of Elementary School Teachers in Shahrekord. Journal of Health Literacy. 2019;4(1):25-32. [DOI:10.22038/ jhl.2019.38770.1039]

4. Peterson, ICD. \&Deal, T.E. Shaping school culture field book. 
San Francisco: Jossey-Bass.2002.

5. Deal, T. E. Schools as cultural arenas: Symbols and symbolic activity. In S. B. Bacharach \& B. Mundell (Eds.), Images of schools: Structures and roles in organizational behavior. Thousand Oaks, CA: Sage. 1995

6. Gruenert, stive. Shaping a new school culture. Contemporary education. 2009;71(2):13-14.

7. Fullan, M. Eight forces for Leaders of Change, Journal of Staff Development. 2005;26(4):54-64.

8. Hargreaves, D. H. School culture, school effectiveness and school improvement. School Effectiveness and School Improvement. 1995;6: (1), 23-46. [DOI:10.1080/0924345950060102]

9. Higgins-D’Alessandro A, Barr JJ. Adolescent empathy and prosocial behavior in the multidimensional context of school culture. The Journal of Genetic Psychology. 2007;168(3):231-50. [DOI:10.3200/GNTP.168.3.231-250] [PMID]

10. Wagner, C. R. The school leader's tool for assessing and improving school culture. Principal Leadership. 2006; 7 (4), 41-44.

11. Firestone, W. A. \& Louis, K. S. School as cultures. In J. Murphy, \& K. S. Louis (Eds.), Handbook of Research on Educational Administrator: A Project to the American Educational Research Association. San Francisco: JosseyBass.1999;2: 297-322

12. Feldman MP, Desrochers P. Truth for its own sake: academic culture and technology transfer at Johns Hopkins University. Minerva. 2004;42(2):105-26. [DOI:10.1023/ B:MINE.0000030019.99709.a0]

13. Taslimi, Mahnaz \& el. Factors, Shaping Fields and Typology of Organizational Culture of School on Tehran City. Journal of Education and Practice.2018:9(8): 62-72.

14. Alami A, Zarei F, Tehrani H, Hosseini Z, Jafari A. Perceived challenges of the schools iron aid national plan from stakeholder perspectives. Tehran University Medical Journal. 2019;77(4):257-66.

15. Mostafaei D, Aryankhesal A, Dastoorpoor M, Rahimikhalifekandi Z, Estebsari F. Patient Safety Culture Assessment of Clinical and Paraclinical Staff Perspective in Selected University of Medical Sciences Hospitals in Tehran. Iranian Journal of Health Education and Health Promotion. 2018;6(3):293-301. [DOI:10.30699/acadpub. ijhehp.6.3.293]

16. Sepidarkish M, Nedjat S, Haghjou L, Mounesan L, Shokri F, Almasi-Hashiani A, et al. Characteristics of a School-Based Program to Promote Physical Activity in Adolescents and Interventional FrameWork: A Qualitative Study. Iranian Journal of Health Education and Health Promotion. 2017;5(2):90-101. [DOI:10.30699/acadpub.ijhehp.5.2.90]

17. Hosseini, Akram. The Effect of Establishment of the Health Promoting Schools System on Improving the Health Level of Mazandaran Students, International Conference on Science and Engineering, Emirates - Dubai, Vida Institute of Ideas.2015.

18. Ramezani H, Nikbakht H, Nasrollahpour Shirvani S, Ahoei K, Mohsenian $\mathrm{H}$. Effect of health promoting school program in schools of the city of Babol: 2013. Journal of Health. 2016;6(5):547-56.

19. Pourali F, Abbaszadeh M, Chavoshbashi AA, Aghababaeian $\mathrm{H}$, Ansari M, pashaei Asl Y. Implementation of the Healthpromoting Schools Program in Primary and Middle Schools of Tabriz and the impact on Environmental Health Indicators. Journal of Advanced Pharmacy Education \& Research| Oct-Dec. 2014;4(S2).

20. Aghili MMM, Jafari AJ, Zia-oddini H. The Assessment of Establishment and Maintenance of the Health Management System in Schools and Grading for Awarding Stars (HSE-ms). Journal of Isfahan Medical School. 2010;28(107).

21. Shabankhani B, Âbdollahi F. Evaluation of hygienic environmental indexes (educational spaces) in village schools of mazandaran province in 2003. Journal of Mazandaran University of Medical Sciences. 2003;13(41):98-102.

22. Zazuoli M, Abdi M, Ghahramani E, Ghorbanian M. Investigation of environmental indexes of district 1 primary school in Sari, Iran. Iranian Journal of Health and Environment. 2009;2(3):204-13.

23. Juhari, Zahra et al. Investigating the Health Environment of Health Services in Selected Elementary Schools in Tehran. Daneshvar Medical Journal.2000;8(29):33- 38.

24. Hoboubati, Mirzam Mahmoud. The study of the safety and environmental health of elementary schools in Yazd and how to improve it. Journal of Shahid Sadoughi University of Medical Sciences and Health Services.2000;8(4):89 - 93.

25. Coe DP, Pivarnik JM, Womack CJ, Reeves MJ, Malina RM. Effect of physical education and activity levels on academic achievement in children. Medicine \& Science in Sports \& Exercise. 2006;38(8):1515-9. [DOI:10.1249/01. mss.0000227537.13175.1b] [PMID]

26. Ramezani A, Tohidi M, Abbaszadegan M. The effect of one bout of incremental exercise on salivary immunoglobulin A (IgA) of high school students. Archives of Exercise in Health and Disease. 2012;3(1-2):168-72. [DOI:10.5628/ aehd.v3i1-2.116]

27. United Nations. Human development report. The real wealth of nations: pathways of humandevelopment. New York: United Nations Development Programme.2010.

28. Kwan SY, Petersen PE, Pine CM, Borutta A. Healthpromoting schools: an opportunity for oral health promotion. Bulletin of the World Health organization. 2005;83:677-85.

29. Guilbert J. The world health report 2002-reducing 
risks, promoting healthy life. Education for health. 2003;16(2):230. [DOI:10.1080/1357628031000116808] [PMID]

30. Gray et al. Developing a health-promoting school. Health Education Authority. 1999;17-18

31. Haji Babaei, Hamid Reza. The features of the "school I love" are based on the document on the fundamental transformation in education and Breeding, Educational Innovations. $2012 ; 42: 51-74$

32. Tee NP. The Singapore school and the school excellence model. Educational Research for Policy and Practice. 2003;2(1):27-39. [DOI:10.1023/A:1024465302953]

33. Farasatkhah, Maghsoud\& Taslimi, Mahnaz. Investigating the Privatization and Culture of Nonprofit Schools in Tehran, presented at the First International Conference on Educational Management of Iran-Tehran.2015.

34. Hedayati, Fereshte et al. Qualitative Validation of the Conceptual Model of a Healthy School with an Emphasis on Organizational Health. Journal of Research in New Approaches to Educational Management.2017;8(2).

35. Ramdass, Mala\& Lewis, Theodore. Towards a model for research on the effects of school organizational health factors on primary school performance in Trinidad \& Tobago. International Journal of Educational Development.2012; 32(3): 482-492. [DOI:10.1016/j. ijedudev.2011.07.002]

36. Ziaee V, Kelishadi R, Ardalan G, Gheiratmand R, Majdzadeh S, Monazzam M. Physical activity in Iranian students CASPIAN Study. Iranian journal of pediatrics. 2006;16(2):157-64.

37. Louise Baur, Stephen M. Twigg, Roger S. A Modern Epidemic: Expert Perspectives on Obesity and Diabetes.by Sydney university press.2012;147-158.

38. Ross C \& Willigen M. Education and the subjective quality of life. Journal of Health andSocial Behavior.1997; 38(3): 275-97. [DOI:10.2307/2955371]

39. Schipper TM, de Vries S, Goei SL, van Veen K. Promoting a professional school culture through lesson study? An examination of school culture, school conditions, and teacher self-efficacy. Professional Development in
Education. 2020;46(1):112-29. [DOI:10.1080/19415257.2 019.1634627]

40. Tajiddini, Malahat, et al. The relationship between organizational culture and personnel HSE performance in a production company: A case study in Saipa Car Company. Journal of Health and Safety at Work. 2012;2(3):71-84.

41. Marchand A, Haines VY, Dextras-Gauthier J. Quantitative analysis of organizational culture in occupational health research: a theory-based validation in 30 workplaces of the organizational culture profile instrument. BMC Public Health. 2013;13(1):443. [DOI:10.1186/1471-2458-13443] [PMID] [PMCID]

42. Deschesnes $M$, Trudeau F, Kébé $M$. Factors influencing the adoption of a health promoting school approach in the province of Quebec, Canada. Health Education Research. 2010;25(3):438-50. [DOI:10.1093/her/cyp058] [PMID]

43. Inchley J, Muldoon J, Currie C. Becoming a health promoting school: evaluating the process of effective implementation in Scotland. Health promotion international. 2007;22(1):65-71. [DOI:10.1093/heapro/ dal059] [PMID]

44. Jessie-Lee D. Mclsaac J-LD, Read K, Veugelers PJ, Kirk SF. Culture matters: a case of school health promotion in Canada. Health promotion international. 2017;32(2):20717.. [DOI:10.1093/heapro/dat055] [PMID]

45. Bennett AE, Cunningham C, Molloy CJ. An evaluation of factors which can affect the implementation of a health promotion programme under the Schools for Health in Europe framework. Evaluation and program planning. 2016;57:50-4. [DOI:10.1016/j.evalprogplan.2016.04.005] [PMID]

46. Zarei, Fatemeh et al. Explaining the strengths, challenges and mechanisms of the Health Promoting Schools Program from the perspective of health experts. Journal of Health Education and Health Promotion.2017; 240-250. [DOI:10.30699/acadpub.ijhehp.5.3.240]

47. Spector BA. The Corporate Culture Survival Guide: Sense and Nonsense About Culture Change. Academy of Management Briarcliff Manor, NY 10510; 2000 